\title{
O uso de livros escolares de matemática nas escolas da imigração alemã durante a Campanha de Nacionalização
}

\section{The use of textbooks of mathematics in schools of german immigration during of the Campaign of Nationalization}

El uso de libros matemáticos escolares en escuelas de inmigración alemán durante la Campaña de Nacionalización

Débora de Lima Velho Junges ${ }^{1}$

DOI: http://dx.doi.org/10.20435/serie-estudos.v23i49.1121

\begin{abstract}
Resumo: Este artigo tem como objetivo analisar o ritual escolar de utilização do livro escolar, em especial o uso de livros escolares de matemática, que operavam na forma de vida escolar em alunos descendentes de imigrantes alemães no Rio Grande do Sul, no período da Campanha de Nacionalização, compreendido entre 1938 e 1945. As ferramentas teóricas do estudo estão vinculadas a pesquisadores da imigração alemã e às teorizações foucaultianas. O material de pesquisa consiste em narrativas de seis pessoas que estudaram em escolas da imigração alemã no Rio Grande do Sul, no período citado. Os principais resultados da investigação apontam que os livros escolares utilizados antes da Campanha de Nacionalização eram considerados melhores do que aqueles que passaram a ser utilizados posteriormente, porque traziam referências à cultura germânica, e que o uso do livro escolar nas aulas de matemática se constituía em um ritual no qual mecanismos de poder atuavam sobre os alunos descendentes de imigrantes alemães com vistas a disciplinar seus corpos.
\end{abstract}

Palavras-chave: Campanha de Nacionalização; livros escolares; educação matemática.

\begin{abstract}
This article aims to analyze the school ritual of schoolbook use, especially the use of school textbooks of mathematics, which worked in the form of the school life in students descended from German immigrants in the Rio Grande do Sul during the period of the Nationalization Campaign, between 1938 and 1945. The theoretical tools of the study are linked to researchers of German immigration and Foucaultian theorizations. The research material consisting of narratives of six people who studied in schools of German immigration, in Rio Grande do Sul, during the
\end{abstract}

\footnotetext{
${ }^{1}$ Instituto Federal Catarinense (IFC), Campus Fraiburgo, Fraiburgo, Santa Catarina, Brasil.
} 
mentioned period. The main results of the research indicates that the textbooks used prior to the Nationalization Campaign were considered better than those that came to be used, because they brought references to Germanic culture, and that the use of the school book in mathematics classes constituted a ritual in which the mechanisms of power acted upon the descendant students of German immigrants with a view to disciplining their bodies.

Keywords: Campaign of Nationalization; schoolbooks; mathematical education.

Resumen: Este artículo tiene como objetivo analizar el ritual escolar del uso del libro escolar, en especial el uso de libros escolares de matemática, que operaban en la forma de vida escolar en alumnos descendientes de inmigrantes alemanes en Rio Grande do Sul, en el período de la Campaña de Nacionalización, comprendido entre 1938 y 1945. Las herramientas teóricas del estudio están vinculadas a investigadores de la inmigración alemana ya las teorizaciones foucaultianas. El material de investigación consiste en narrativas de seis personas que estudiaron en escuelas de la inmigración alemana en Rio Grande do Sul, en el período citado. Los principales resultados de la investigación apuntan que los libros escolares utilizados antes de la Campaña de Nacionalización eran considerados mejores que aquellos que pasaron a ser utilizados posteriormente, porque traían referencias a la cultura germánica, y que el uso del libro escolar de matemática se constituía en las clases un ritual en el cual mecanismos de poder actuaban sobre los alumnos descendientes de inmigrantes alemanes con miras a disciplinar sus cuerpos.

Palabras clave: Campaña de Nacionalización; libros de la escuela; educación matemática.

\section{INTRODUÇÃO}

A Campanha de Nacionalização, que iniciou com os decretos de 1938 relacionados à restrição do uso do português como língua única do país e culminou em 1945, é considerada por estudiosos e pesquisadores da imigração alemã no Brasil como um dos elementos que intervieram no declínio das escolas da imigração alemã no território nacional e consequente fechamento destas em colônias alemãs (KREUTZ, 1994; RAMBO, 1994). Nesse período, que coincide com a Segunda Guerra Mundial, se tornou proibida a fala da língua alemã e de suas variações linguísticas no território brasileiro, proibição essa estabelecida por uma série de decretos-lei instituídos tanto em âmbito federal, quanto estadual (no caso específico desta pesquisa, o Estado do Rio Grande do Sul), e que repercutiu diretamente na vida daqueles imigrantes e de seus descendentes que utilizavam a língua alemã para se comunicarem.

Tais medidas, que tinham como principal finalidade difundir os ideais nacionalistas e integrar a população "étnica" à nação, trouxeram dificuldades às comunidades e a diversos setores econômicos e sociais, como, por exemplo, a imposição de que o comércio colonial, as associações, as igrejas e as escolas não 
O uso de livros escolares de matemática nas escolas da imigração alemã durante a Campanha de Nacionalização

deveriam mais utilizar uma língua que não fosse a portuguesa. Em relação às escolas da imigração alemã, nas quais o ensino era exclusivamente feito em língua alemã ou bilíngue (alemão-português), a adequação às novas regras não foi um processo simples, já que muitos professores e alunos não sabiam se comunicar em português.

Pela imposição das medidas que buscavam a nacionalização do ensino, "criou-se um clima de tensão e medo na região colonial dos imigrantes, e a proibição da língua materna, que era fator de identificação étnico-cultural e religiosa, atingiu a nova geração que passou a um constrangedor silêncio sobre a própria identidade" (KREUTZ, 2010, p. 81-2). Além disso, "a escola se tornou estranha para o aluno da imigração, seja pela língua, seja pelo método de ensino" (KREUTZ, 2010, p. 82), uma vez que, nos estabelecimentos de ensino, as imposições do Estado provocaram o afastamento de professores que não estavam de acordo com as exigências legais para o oficio, e os materiais didáticos que eram escritos em língua estrangeira foram substituídos por exemplares em português e aprovados por conselho estadual.

Diante das legislações do Estado em relação à proibição de livros escolares $^{2}$ escritos na língua alemã e da obrigatoriedade do uso de livros nacionais nas escolas da imigração alemã, esta pesquisa procurou discutir os impactos que essas imposições ocasionaram no ritual $^{3}$ escolar de utilização do livro escolar, em especial na utilização de livros escolares de matemática, que operavam na forma de vida escolar em alunos descendentes de imigrantes alemães no Rio Grande do Sul, no período da Campanha de Nacionalização. Para tanto, foram analisadas as

\footnotetext{
2 Utilizo a expressão "livro escolar" em conformidade com Kreutz (2008). O autor observa que esta expressão é a tradução direta de Schulbuch, termo mais recorrente na literatura dos imigrantes alemães. Entretanto também foram utilizados no período "livros didáticos" e "manuais escolares" como sinônimo de "livros escolares".

${ }^{3}$ Os rituais, em conformidade com Foucault (2010), são entendidos como procedimentos que legitimam a manifestação da verdade, sejam eles na ordem do dito, do enunciado ou do que foi expresso, como também de outros procedimentos postos em ação na prática social. O filósofo considera que a expressão "ritual" se refere a dois conjuntos de procedimentos da manifestação da verdade, sejam eles verbais ou não: o primeiro, para que o sujeito tenha acesso às informações, aos saberes e aos conhecimentos mais atualizados; e um segundo conjunto de procedimentos, para atualizar o que é colocado como verdadeiro, "seja por oposição a um falso que foi eliminado, discutido, refutado etc.", ou "por revelação ou ocultação, por dissipação disso que é esquecido, por conjuração de imprevisível” (FOUCAULT, 2010, p. 25).
} 
narrativas produzidas com seis pessoas que estudaram em escolas da imigração alemã do estado gaúcho, no período citado.

A especificidade em relação ao uso de livros escolares de matemática se dá, na medida em que se observa que o ensino da matemática apresentava certo destaque em relação a outras disciplinas da grade curricular nas escolas da imigração alemã. Um exemplo são as pesquisas de Kreutz (1994) e Rambo (1994) ao indicarem que, desde a formação das primeiras escolas, o estudo do "cálculo" mereceu substancial atenção na formação dos currículos durante o processo de escolarização decorrente do estabelecimento de imigrantes alemães no Rio Grande do Sul.

Várias razões explicam o lugar privilegiado do cálculo no currículo escolar, dentre elas a de que "a familiaridade e o manejo do cálculo, ao menos até o nível de juros simples e compostos, da regra de três e outros, representava o mínimo de ferramental, indispensável para a solução dos múltiplos problemas do dia-a-dia" (RAMBO, 1994, p. 155). Aquilo que Rambo (1994) denomina como "caráter utilitarista da matemática" também é afirmado por Kreutz (1994) quando da análise de livros e manuais didáticos utilizados nas escolas da imigração alemã, evidenciando, ainda mais, o lugar de destaque do cálculo no currículo escolar.

Essas observações indicam que o estudo do cálculo foi uma das preocupações no processo de escolarização dos imigrantes alemães e de seus descendentes, mesmo que de forma incipiente, quando da formação das primeiras escolas. E, além disso, a matemática estudada era atrelada com a "realidade" do aluno e da comunidade ${ }^{4}$.

\section{O PERÍODO DA CAMPANHA DE NACIONALIZAÇÃO E AS ESCOLAS DA IMIGRAÇÃO ALEMÃ}

A política educacional do período do Estado Novo (1938-1945), durante o governo de Getúlio Vargas, que ficou conhecida como Campanha de Nacionalização, impactou diretamente o funcionamento e a rotina das escolas da imigração alemã. Tal estratégia governamental marcou a fase final das ditas "escolas estrangeiras" (RAMBO, 1994).

\footnotetext{
${ }^{4}$ Acompanho a discussão de Duarte (2009) em relação ao uso da expressão "realidade", "entendendo-a não de forma tranquila como algo que preexista fora do domínio da linguagem e que possua uma essência que a caracterize" (DUARTE, 2009, p. 20).
} 
Em termos de legislação no Estado do Rio Grande do Sul, Kreutz (2010) considera o decreto n. 7.212 de 6 de abril de 1938, como uma das primeiras leis específicas direcionadas à nacionalização compulsória do ensino. Em relação ao decreto, os principais itens relacionados às escolas da imigração são: a obrigatoriedade da alocação, em escolas onde o ensino ocorresse em língua estrangeira, de professores designados pela Secretaria da Educação para o ensino das matérias de língua portuguesa, História e Geografia brasileira e educação cívica e moral; ações punitivas que incluíam o fechamento das escolas que não conseguissem cumprir essas prescrições; e a proibição de afixação de cartazes em língua estrangeira e homenagens a personalidades estrangeiras.

Entretanto tal decreto permitia a manutenção da língua estrangeira nas escolas da imigração, o que conflitava com as legislações federais que aferiam sobre o mesmo assunto (PAIVA, 2003). Esse "problema" foi resolvido com a publicação do decreto n. 7.614, em 12 de dezembro de 1938, que passou a regulamentar o ensino particular. Além de ratificar o que já havia sido previsto no decreto $\mathrm{n}$. 7.212, o artigo 70 da nova lei determinava que o ensino primário passasse a ser ministrado exclusivamente em português, proibindo o ensino e o emprego de língua estrangeira no turno de trabalho ou fora dele.

Em âmbito federal, entre 1938 e 1939, o Estado Novo promoveu uma série de decretos-lei inseridos na política de Nacionalização do Ensino. O primeiro foi o decreto-lei n. 406, de 4 de maio de 1938, conhecido como Lei da Nacionalização, que dispunha sobre a entrada de estrangeiros em território nacional (KREUTZ, 2010). Nesse documento, o artigo 93 determinou que, nas escolas rurais do país, o ensino de todas as matérias deveria ser ministrado em português. Ainda, todos os livros destinados ao ensino primário deveriam ser escritos na língua portuguesa (instrução reforçada pelo decreto-lei n. 1006, de 30 de dezembro de 1938, que estabeleceu as condições de produção, importação e utilização do livro didático e indicava como impedimento para a autorização do uso de livros didáticos aqueles que não estivessem escritos na língua nacional); e se tornou obrigatório o ensino de História e Geografia do Brasil nos cursos primários e secundários.

Nessa conjuntura política na qual o estrangeirismo passou a ser tratado como assunto de segurança nacional, a Nacionalização do Ensino foi estabelecida oficialmente no dia 18 de novembro do mesmo ano, por meio do decreto-lei n. 868, que criou, no Ministério da Educação e Saúde, a Comissão Nacional 
de Ensino Primário. Esta tinha como uma de suas competências definir ações a serem exercidas "pelo Governo Federal e pelos governos estaduais e municipais para o fim de nacionalizar integralmente o ensino primário de todos os núcleos de população de origem estrangeira" (artigo 2으, inciso b).

Em 1939, o decreto-lei n. 1545, de 25 de agosto, considerado por Dreher (1994) e Kreutz (2010) como o mais importante do período, tratava da adaptação dos brasileiros descendentes de estrangeiros ao meio nacional "pelo ensino e pelo uso da língua nacional, pelo cultivo da história do Brasil, pela incorporação em associações de caráter patriótico e por todos os meios que possam contribuir para a formação de uma consciência comum" (artigo 1ㅇ). No que se referia às atribuições diretas do Ministério da Educação e Saúde, eram indicadas: a criação de escolas brasileiras nas regiões com núcleos de estrangeiros e seus descendentes; recrutar professores para atuarem em escolas pertencentes a essas regiões; subvencionar as escolas vinculadas à imigração, principalmente no que tangia ao ensino de línguas, de História e Geografia do Brasil. Esse decreto-lei ainda proibia que estrangeiros assumissem cargos relacionados à gestão das escolas e reforçava a tarefa dos professores, de estimularem e difundirem entre seus alunos o sentimento nacional e o patriotismo.

Houve outras legislações posteriores a essas que reforçavam as intenções do Estado de impulsionar a política de subvenção do ensino privado e colocar em prática ações que procuravam subjetivar os imigrantes alemães e seus descendentes, a fim de que incorporassem o espírito nacionalista- pois, até então, os imigrantes eram tidos como pessoas não incorporadas ao restante da população brasileira pelo uso da língua alemã e, ainda, pela conservação de hábitos e costumes culturais provenientes de seu país de emigração (GERTZ, 1991).

O discurso da Campanha de Nacionalização foi sustentado principalmente pelo sentimento de "perigo" dos estrangeiros e dos professores da imigração alemã, e influenciou os pensamentos dos jovens através da escolarização (divulgando, por exemplo, o germanismo e o nazismo). Também "pelo projeto nacionalista do Estado Novo que propunha a uniformização, a padronização cultural e a supressão de formas de organização autônoma da sociedade" (QUADROS, 2006, p. 54).

O uso do idioma nas escolas das comunidades de imigrantes alemães era uma característica presente e marcante que estava associada ao Deutschtum (germanismo), uma consciência identitária de representação do mundo teutônico 
(SEYFERT, 1982). A partir da segunda metade do século XIX e até as quatro primeiras décadas do século XX, o germanismo refletiu no pensamento dos professores e religiosos que vinham atuar nas escolas e comunidades alemãs no Rio Grande do Sul. Essa é apontada por Kreutz (2010) como uma das condições de possibilidade da permanência do alemão como a língua de ensino nas escolas da imigração alemã, ao passo que o português era ministrado na condição de segunda língua (BREDEMEIER, 2010).

A preocupação do Estado pela permanência do uso da língua alemã mesmo em território brasileiro incitou discussões de alguns cronistas já na segunda metade do século XIX (LORENZ; VECHIA; FERREIRA, 2008), como por exemplo, Demétrio Acácio Fernandes da Cruz, que, em 1863, analisando a situação da colônia de São Leopoldo do Rio Grande do Sul, escreveu que "com prelados e professores alemães, têm os seus filhos brasileiros natos, sido criados pelo sistema, usos e costumes e linguagem germânica [...] e guardam com toda a pureza e patriotismo o idioma de seu país natal" (CRUZ, apud LORENZ; VECHIA; FERREIRA, 2008, p. 4).

Atentando para o contexto sul-rio-grandense, Rambo (1994) considera que as ações postas em operação pelo Estado no âmbito educacional foram um golpe "brutal" e "precipitado" que causou "danos irreparáveis". Dentre essas, o autor argumenta que "a nacionalização intempestiva resultou de fato numa geração de quase analfabetos" (RAMBO, 1994, p. 83), isso em decorrência da proibição da comunicação em alemão nas escolas e do uso de materiais didáticos escritos na língua alemã, dificultando o ensino daqueles que, antes de mais nada, precisavam aprender a falar em português.

Das aproximadamente mil escolas provenientes da imigração alemã existentes em 1938, restaram no máximo 200 com o fim da Segunda Guerra Mundial. "As demais, ou se transformaram em escolas públicas, ou fecharam" (RAMBO, 1994, p. 81). Contudo o fechamento dessas escolas não ocorreu simplesmente em decorrência da Campanha de Nacionalização promovida pelo governo (KREUTZ, 1994).

O acontecimento da Campanha de Nacionalização precipitou o processo ao instituir medidas nacionalistas exacerbadas e com a política de concorrência na abertura de escolas públicas em núcleos formados por imigrantes alemães e seus descendentes. Entretanto "naquele período estavam presentes outros fatores de pressão para transformar a organização escolar" (KREUTZ, 1994, p. 56), fatores como a necessidade do aprendizado da língua portuguesa e de um maior contato 
com o restante do povo para a manutenção da vida social que, possivelmente, conduziriam ao fechamento ou à reorganização de muitas escolas da imigração alemã.

\section{PROCEDIMENTOS TEÓRICO-METODOLÓGICOS}

Conforme mencionado anteriormente, a Campanha de Nacionalização teve grandes implicações para as comunidades de imigração alemã, em especial, produzindo tensionamentos em escolas situadas nesse contexto. Tal período temporal se constitui como relevante na trajetória da escolarização da imigração alemã. Por essa razão, foi definido como sujeitos desta pesquisa um grupo de pessoas que frequentaram escolas da imigração alemã no período da Campanha de Nacionalização, entre 1938 e 1945.

O grupo de seis ${ }^{5}$ participantes foi entrevistado durante o ano de 2013, sendo que os participantes tinham idades que variavam de 78 a 85 anos. O grupo era dividido em quatro mulheres e dois homens que residiam em Parobé e Taquara no momento das entrevistas, municípios gaúchos pertencentes à microrregião do Vale do Paranhana.

Para a produção do material empírico, foi utilizado como estratégia de pesquisa a entrevista individual com cada um dos participantes, que inicialmente foram gravadas e depois transcritas ${ }^{6}$. Em todos os casos, foram realizadas mais de duas entrevistas com o mesmo participante para complementar discussões iniciadas e rever certos pontos que poderiam ser mais bem desenvolvidos com a elaboração de novas questões provocativas.

Metodologicamente, as entrevistas foram conduzidas de forma que os sujeitos se narrassem, ou seja, com o objetivo de que as narrativas produzidas estivessem em conformidade com os preceitos da Storytelling (JØRGENSEN; BOJE, 2010).

\footnotetext{
${ }^{5}$ Para manter o anonimato dos participantes da pesquisa, eles foram identificados pelos seguintes nomes: Helga, Veni, Rose, Renata, Breno e Germano.

${ }^{6}$ Cabe aqui também ressaltar que todos os sujeitos assinaram o Termo de Consentimento Livre e Esclarecido após serem informados sobre os objetivos da pesquisa, em acordo às normas de ética nas pesquisas em ciências humana e sociais. Além disso, o projeto passou pelo Comitê de Ética em Pesquisa e foi aprovado, por estar adequado ética e metodologicamente, conforme os preceitos da Resolução 466/12 do Conselho Nacional de Saúde.
} 
A Storytelling é a linguagem e a história viva (JØRGENSEN; BOJE, 2010). Ou seja, uma narrativa para ser compreendida como Storytelling, não conduz a fala dos entrevistados de forma a se elaborar um texto linearizado (com um começo, meio e fim), na qual a única preocupação do pesquisador é atingir os objetivos da pesquisa. Na perspectiva da Storytelling aquele que fala passa a ter a liberdade de contar a sua história, da forma que lhe é conveniente.

Assim, nem toda narrativa se constitui como uma Storytelling. Na percepção de Jørgensen e Boje (2010), cada vez mais as narrativas produzidas nas mais diversas organizações são limitadas por caminhos a serem seguidos rigorosamente. "Qualquer começo, meio e fim de um texto representa uma ilusão de encerramento" (JØRGENSEN; NUNEZ, 2010, p. 257). Desse modo, a delimitação do que falar e de como estruturar a fala inibe o interlocutor. Na produção das narrativas, procuramos nos afastar da realização de entrevistas estruturadas que produzissem narrativas focadas no objetivo da pesquisa, já que estas possuem um enfoque menos subjetivo (JØRGENSEN; NUNEZ, 2010).

Por se constituir como uma prática discursiva, a narrativa e, consequentemente, a perspectiva da Storytelling, também está imbricada em relações de poder (JØRGENSEN; NUNEZ, 2010), poder esse que é construído socialmente e regula, seleciona, organiza e redistribui a produção do discurso (FOUCAULT, 1998).

O "poder não se encontra somente nas instâncias superiores de censura, mas penetra muito profundamente, muito sutilmente em toda a trama da sociedade" (FOUCAULT, 2002, p. 71), ele está em toda a parte, operando sobre os sujeitos e na produção dos discursos, inseridos em um campo de lutas. Portanto não há neutralidade nos discursos, pois quem diz, o faz a partir de um lugar instituído historicamente. Assim, a narração como uma prática discursiva também se submete aos procedimentos organizacionais, seletivos e restritivos de proferimento das palavras (FOUCAULT, 1998). Nessa perspectiva, a narrativa é compreendida em termos de relação do narrador consigo e com os outros operando em determinados tempos e espaços (JØRGENSEN; NUNEZ, 2010).

\section{EVIDÊNCIAS DA CULTURA ALEMÃ NOS LIVROS ESCOLARES}

A fim de discutir o uso do livro escolar, mais especificamente o uso de livros escolares de matemática, como um ritual escolar nas escolas da imigração alemã, inicio esta seção analisando as narrativas de três participantes da 
pesquisa que evidenciam o uso de livros escolares antes e depois da Campanha de Nacionalização, que decretou censura aos livros usados nas redes de ensino, assim como também proibiu a importação e impressão de livros em língua estrangeira (QUADROS, 2006).

Nas três narrativas, é possível perceber que os livros escolares anteriores à Campanha de Nacionalização traziam elementos que se referiam à cultura alemã, mesmo aqueles impressos em português. Esses livros eram considerados, pelos participantes, melhores do que aqueles que passaram a ser utilizados posteriormente, porque estes últimos não traziam referências à cultura alemã, referências que eram valorizadas pelos alunos das escolas da imigração alemã.

Renata observou que os livros escolares utilizados em sua escola antes da Campanha de Nacionalização eram, em sua maioria, escritos em alemão. Segundo ela, "a gente aprendia muitas coisas da vida alemã nesses livros, e eu gostava porque nasci lá, né e fazia parte das minhas raízes. Mas não é que tinha coisas só da Alemanha não, eles falavam do Brasil também, mas eles não eram só das coisas do Brasil como aconteceu mais tarde". Ela recordou que, na sua avaliação e de seus colegas, estes livros eram melhores: "é que eles também achavam os livros que a gente tinha antes melhor, porque fazia a gente aprender coisas da nossa terra natal".

A mesma avaliação é realizada por Germano em relação aos livros escolares anteriores às medidas nacionalistas: "porque assim, na escola a gente aprendeu também das coisas de lá, e nesses livros tinha. Eram bons. Mas aí depois esses livros a gente não podia mais usar, aí a gente só aprendia da história do Brasil, do português, dos estudos daqui mesmo. Não tinha mais nada que falava dos alemães. Uma pena, porque aqueles livros eram melhores".

Helga destacou que as referências da cultura alemã presentes nos livros escolares eram importantes para ela e seus colegas, pois "em algumas coisas eles falavam das coisas que eram da cultura dos alemães, da nossa origem, e isso era bom pra poder manter as tradições com nós, até mesmo no colégio".

Tais narrativas apontam que para os imigrantes alemães e seus descendentes, preservar o Deutschtum era algo significativo em suas vidas e estava relacionado à manutenção de uma nacionalidade alemã, mesmo sendo cidadãos brasileiros. Nesse contexto, as escolas da imigração alemã estabeleciam uma espécie de vínculo entre os alunos descendentes de alemães e a cultura alemã 
com o uso de livros escolares que traziam referências a esta cultura, reforçando a preservação do Deutschtum.

Os estudos realizados por Kreutz a respeito do uso dos livros escolares nas escolas da imigração alemã ajudam a compreender a relevância dos livros no processo educacional vinculado à imigração alemã no Rio Grande do Sul. Em suas pesquisas, ele observou que a produção e a utilização de livros escolares como ferramenta pedagógica estavam relacionadas à manutenção de uma tradição que os imigrantes alemães trouxeram da Alemanha, visto que lá os livros e as cartilhas didáticas eram amplamente utilizados em suas escolas. "Provindos dessa tradição já secular em relação à importância da literatura escolar, os imigrantes alemães no Rio Grande do Sul investiram intensamente na elaboração e na impressão de livros didáticos" (KREUTZ, 2008, p. 30).

Em parte, os livros escolares utilizados no Rio Grande do Sul eram produzidos e impressos na Alemanha, principalmente no início do processo escolar. Com a fundação de editoras e da imprensa educacional periódica dos imigrantes alemães no Rio Grande do Sul, grande parte dos livros escolares eram produzidos no próprio estado e distribuídos para o restante do país (KREUTZ, 2008).

A partir de 1870, "a questão da elaboração do material didático começou a ter incentivo especial da parte das lideranças da imigração alemã, especialmente das igrejas cristãs, católica e evangélica" (KREUTZ, 2008, p. 39). Além disso, "as assembleias gerais e regionais de professores tiveram como tema forte de suas reuniões a elaboração e o uso dos livros didáticos, [...] com a edição de manuais preparados especificamente para as necessidades das escolas étnico-comunitárias" (KREUTZ, 2008, p. 40).

Conforme consta na documentação ligada à imigração alemã, uma das preocupações relacionadas aos livros escolares que foram empregados em suas escolas é que esses deveriam ser adequados às especificidades da forma de vida dos imigrantes alemães. "Dizia-se que os manuais didáticos da Alemanha não serviam no Brasil, que a realidade aqui era diferente da alemã, seria preciso trabalhar com símbolos daqui, engajando os alunos na realidade brasileira" (KREUTZ, 1999, p. 152). Tais discussões se encontram redigidas especialmente nos periódicos (jornais e revistas) destinados aos professores da época que eram um meio de comunicação entre os docentes, de divulgação de materiais pedagógicos e apresentavam propostas de metodologia de ensino. 
Analisando o conteúdo dos livros escolares utilizados até 1938 nas escolas da imigração alemã, Kreutz (1999) considera que estes tratavam de questões relacionadas ao contexto histórico e geográfico do Brasil, assim como também abordavam os símbolos nacionais brasileiros. Entretanto, eles não tratavam exclusivamente da cultura brasileira. Eram trabalhadas simultaneamente "referências étnico-culturais alemãs, no modo de ser da alma alemã" (KREUTZ, 1999, p. 152). Algo que foi referenciado pelos participantes desta pesquisa e que era tido como algo positivo na avaliação deles, pois remetia à sua descendência alemã.

No processo de nacionalização do ensino durante o governo de Getúlio Vargas, legislações a respeito dos livros escolares foram elaboradas e implementadas, atingindo diretamente as escolas da imigração alemã. O decreto-lei federal n. 406, de maio de 1938, estabelece que "os livros destinados ao ensino primário serão exclusivamente escritos em língua portuguesa" (Artigo 85, inciso 3ํ). 0 mesmo decreto ainda prevê que "nas zonas rurais no país não será permitida a publicação de livros, revistas ou jornais em língua estrangeira, sem permissão do Conselho de Imigração e Colonização" (Artigo 86). No mesmo ano, o decreto-lei n. 1006, de dezembro, estabelece que "não se concederá autorização, para uso no ensino primário, de livros didáticos que não estejam escritos na língua nacional" (Artigo 22). Por fim, o decreto-lei n. 3.580, de 3 de setembro de 1941, determina que "fica proibida a importação de livros didáticos, escritos total, ou parcialmente em língua estrangeira, se destinados ao uso de alunos do ensino primário, bem como a sua produção no território nacional” (Artigo 4).

A partir dessas medidas, a grande maioria dos livros escolares utilizados nas escolas da imigração alemã foram substituídos por outros que estivessem em conformidade com as exigências legais. Muitos livros "foram destruídos pelos agentes de nacionalização e também pelos próprios imigrantes como autodefesa" (KREUTZ, 2010). Nesse período "a maioria dos livros didáticos escritos em língua alemã foi queimada pelas famílias intimidadas por guardá-los em suas casas ou ainda, pelas autoridades policiais que realizaram buscas em escolas, bibliotecas e junto às residências dos professores" (BIEMBENGUT; GAERTNER, 2011, p. 177).

Renata narrou com pesar a queima dos livros escolares que presenciou em sua escola: "eu lembro que fiquei muito horrorizada quando na escola eles queimaram todos os livros que eram escritos em alemão, por causa da guerra. Eles pegaram todos os livros e fizeram uma fogueira nos fundos na escola. Foi 
O uso de livros escolares de matemática nas escolas da imigração alemã durante a Campanha de Nacionalização

tudo queimado. Ninguém falou nada, só ficou olhando aquelas páginas e páginas pegando fogo".

\section{O USO DOS LIVROS ESCOLARES DE MATEMÁTICA}

No contexto das escolas da imigração alemã, o uso de livros escolares de matemática era amplamente difundido (KREUTZ, 2008). No período de 1870 até 1939, foram produzidos pelas editoras nacionais livros tanto em português quanto em alemão direcionados à forma de vida dos alunos descendentes de alemães. Em alguns casos, foram registrados números consideráveis de tiragem de livros escolares de matemática, o que indica a adoção de tais materiais didáticos pelas escolas da imigração alemã. Um exemplo, é a obra de aritmética de Otto Büchler intitulada Praktische Rechenschule. Esse livro "se pode constatar por meio do jornal Das Schulbuch, foi bem aceito na instrução escolar alemã no RS, por um longo período, sendo provavelmente o livro de maior tiragem do gênero" (MAURO, 2005, p. 129).

Foge ao objetivo deste artigo analisar os livros escolares quanto aos conteúdos matemáticos abordados por eles. Mas é relevante observar que os livros adotados pelas escolas da imigração alemã, antes das medidas nacionalizadoras, traziam elementos da cultura alemã em sua redação (MAURO, 2005), elementos estes que eram valorizados pelos participantes desta pesquisa e, de acordo com suas narrativas, também eram considerados relevantes por seus colegas descendentes de alemães.

Como narraram os participantes, no enunciado dos problemas matemáticos contidos nos livros escolares, havia traços da cultura alemã que os remetiam a sua descendência e que para eles tornava os livros mais próximos à vida na colônia, marcada pelos costumes e tradições alemãs. "Os livros dessa época eram bons porque tinha exemplos de coisas que era bem da colônia, da nossa origem. Todos gostavam" (Veni). Referências à plantação, à venda de produtos coloniais, medição de terra, nomes dos personagens e também à receita de uma torta de maçã tradicional alemã foram algumas das menções citadas pelos participantes.

No caso de Breno, é interessante a distinção que ele estabeleceu entre os livros editados em português e em alemão: "isso era bom, porque a cartilha trazia as nossas tradições e valorizava o que era da nossa vida. Por isso era bom também que os livros eram em alemão. Depois mudou e foi tudo pro português e das coisas 
do Brasil. Não era a mesma coisa, porque as cartilhas eram iguais pra todo mundo, não tinha mais aquela diferença da cartilha dos brasileiros e de nós da colônia".

Após as medidas nacionalizadoras que passaram a proibir livros em alemão ou que trouxessem referências à cultura alemã, alguns livros tiveram que ser substituídos, e os livros adotados pelas escolas da imigração alemã passaram a ser os mesmos que eram utilizados no restante das escolas no país. Na fala de Breno, é possível observar que ele se via como um colono e não como um brasileiro. Além disso, os livros escolares de matemática que eram utilizados na escola que frequentou antes da Campanha de Nacionalização refletem essa percepção de si e eram considerados por ele melhores.

Rose também diferenciou os livros escolares de matemática e avaliou como inferior o livro escrito em português: "eu gostava daqueles livros de matemática, eles não tinham só coisas escritas, eles traziam gravuras também. E essas gravuras tinham a ver com a vida na colônia, que nem figura dos bichos, das galinhas, dos porcos, das árvores. E eles falavam das coisas que a gente usava ou comia, que nem cuca e linguiça [risadas]. Aí quando mudou ficou pior. Não tinha mais nada das coisas da nossa vida".

O segundo ponto a ser destacado a respeito dos livros escolares de matemática se refere ao ritual escolar de utilização dos livros pelos professores das escolas da imigração alemã e que remetem à discussão realizada por Wanderer (2014) sobre os mecanismos disciplinares postos em funcionamento sobre os escolares descendentes de alemães durante o período da Campanha de Nacionalização.

Em sua análise, Wanderer (2014) operou com ferramentas foucaultianas relacionadas às práticas de disciplinamento exercidas no poder disciplinar e utilizou como principal referência Foucault (2004). O filósofo argumenta que a disciplina fabrica corpos dóceis por meio de técnicas essenciais: a arte das distribuições, o controle da atividade, a organização das gêneses e a composição das forças.

Para o filósofo (FOUCAULT, 2004), a arte das distribuições está relacionada à organização dos indivíduos no espaço, e, para isso, o poder disciplinar pode se utilizar, ou não, de cercas e de muros ou de prédios fechados para o enclausuramento dos indivíduos. A disciplina tem a necessidade de dividir um espaço para cada indivíduo, evitando, assim, a formação de grupos ou de aglomeramentos.

A segunda técnica do poder disciplinar diz respeito ao controle rigoroso do tempo empregado nas mais diversas atividades, durante as quais o corpo deve 
O uso de livros escolares de matemática nas escolas da imigração alemã durante a Campanha de Nacionalização

estar totalmente aplicado à execução de sua tarefa. Para tanto, a disciplina ensina a perfeita posição do corpo para que não ocorra perda de tempo e "impõe a melhor relação entre um gesto e a atitude global do corpo, que é sua condição de eficácia e de rapidez" (FOUCAULT, 2004, p. 130).

A terceira técnica se articula com a segunda, pois o poder disciplinar sobre o tempo garante a organização e o controle máximo de todo o processo, com vistas a se alcançar o melhor resultado final do que foi produzido ou aprendido no desenvolvimento das atividades.

Foucault (2004) também argumenta que a organização e que o controle do tempo e do espaço disciplinado passam a compor forças para "construir uma máquina cujo efeito será elevado ao máximo pela articulação combinada das peças elementares de que ela se compõe" (FOUCAULT, 2004, p. 138). Assim, a atividade que cada indivíduo exerce serve a um coletivo e se articula com outro, de modo que a combinação se torna forte e eficiente.

No caso da pesquisa realizada com ex-alunos que frequentaram a escola de Costão no período da Campanha de Nacionalização, Wanderer (2014) observou que cada uma dessas quatro funções disciplinares foi posta em operação como um aparelho eficiente de disciplinamento produzindo sujeitos dóceis e produtivos. Tais estratégias geraram "efeitos de subjetivação nos alunos e alunas não só no espaço escolar, tampouco somente ao longo de suas infâncias, mas fora da escola e em outros períodos de suas vidas" (WANDERER, 2014, 268).

Nos excertos das narrativas dos participantes desta pesquisa também foram identificadas "grandes funções disciplinares" (FOUCAULT, 2004) operando sobre os alunos das escolas da imigração alemã quando da utilização de livros escolares nas aulas de matemática. Primeiramente, é destacado que o espaço escolar era dividido em fileiras, nas quais os alunos sentavam individualmente, o que na compreensão dos participantes ajudava na concentração para a realização das tarefas de matemática: "a gente sentava em filas, todo mundo quietinho" (Breno); "a gente resolvia tudo sozinhos, não dava pra sentar com colega pra resolver, que nem hoje em dia. Naquela época era todo mundo em fila, muito organizado" (Rose); "todos sentavam em fila, sempre individual, que era pra evitar as conversas e pra não virar baderna como acontece nas escolas hoje que não tem mais aquela ordem" (Veni); "todo mundo em fila, um atrás do outro como tinha que ser, todo mundo quietinho" (Helga). Tal organização remete à arte das distribuições, na 
qual "a disciplina atua na disposição espacial, fazendo com que o espaço ocupado pelos indivíduos seja demarcado, quadriculado e dividido pelo número de corpos disponíveis para preenchê-lo" (WANDERER, 2014, p. 121).

O uso do livro escolar de matemática ocorria em um momento específico das aulas e o tempo das aulas era distribuído mantendo sempre um determinado padrão. Conforme narraram os participantes, as aulas eram iniciadas com o professor expondo o conteúdo matemático a ser estudado naquela aula. Após a explicação verbal, o professor determinava as páginas dos livros a serem lidas e os exercícios que deveriam ser resolvidos em um tempo pré-determinado. Terminado esse tempo, o professor passava ao momento de correção dos exercícios.

Essa distribuição do tempo pode ser observada nas três narrativas a seguir: "o professor explicava o que a gente ia estudar naquela aula. Depois que ele explicava, ele passava as contas do livro pra gente fazer. [...] No fim se corrigia, com o professor passando a correção" (Breno); "a professora explicava, aí pedia pra gente ler o que tinha no livro daquela matéria e depois dizia quais contas a gente tinha que resolver. Aí a gente resolvia e depois ela passava as respostas pra nós na lousa" (Rose); "a professora começava a aula explicando o conteúdo no quadro e passava os exercícios pra nós que era do livro. Era sempre assim" (Veni).

Essa divisão do tempo das aulas de matemática "refere-se ao controle da atividade, buscando um máximo aproveitamento do tempo que a investe e também do corpo que a desenvolve" (WANDERER, 2014, p. 122). O momento da explicação pelo professor, o momento do uso do livro escolar, dividido entre leitura do conteúdo e realização dos exercícios, e o momento da correção dos exercícios eram os três intervalos de tempo que demarcavam as aulas de matemática e tinham que ser cumpridos rigorosamente por todos.

Além disso, o uso do livro escolar estabelecia a classificação dos alunos de acordo com seu nível, o que remete à terceira função disciplinar que é a organização das gêneses. A cada ano escolar, um livro diferente era empregado seguindo a série em que se encontrava o aluno, definindo a diferenciação das aprendizagens conforme o tempo de escolarização. Segundo Breno, "nas aulas de matemática a gente usava as cartilhas pra estudar e fazer os exercícios. Era sempre muitas contas pra fazer e cada ano ia ficando cada vez mais difícil. Um livro mais difícil".

Por fim, a quarta função disciplinar que consiste na "constituição de uma rede de forças que atuam em todos os momentos da vida dos estudantes visando 
à produção da disciplina" (WANDERER, 2014, p. 127), é observada nas seguintes falas dos participantes: "depois que ele explicava, ele passava as contas do livro pra gente fazer. E ficava nos cuidando pra ver se ninguém espiava a tarefa que o colega estava fazendo. Não podia perguntar, nem falar com os colegas. Essa hora era a hora do estudo, tinha que se concentrar par fazer tudo direitinho e com capricho. E todo mundo sabia o que fazer, o professor não precisava ficar falando" (Breno); "daí a professora começava a aula explicando o conteúdo no quadro e passava os exercícios pra nós que era do livro. Era sempre assim. O bom era que não tinha muita conversa nas aulas, ai se conseguia aprender melhor e a gente já sabia que era assim que funcionava nas aulas de matemática. A rotina da aula, entende?" (Veni); "era a página inteira cheia de contas de matemática, e a gente tinha tempo pra fazer tudo, que, se não fizesse, podia levar xingão. Aí não era bom. Mas acho que não tinha ninguém que não fazia os deveres, já era do costume fazer tudo conforme mandava o professor. É, funcionava bem as aulas e ninguém esquecia do livro também" (Helga).

Nos trechos destacados, é possível identificar que a rotina das aulas de matemática, na qual o uso do livro escolar era instituído como uma prática recorrente, não era ditado apenas pelo professor, mas fazia parte do que esperavam os alunos das aulas de matemática, uma vez que estes se encontravam como atuantes nesse processo e tinham como verdade que essa metodologia de ensino e de aprendizagem era adequada no contexto em que estavam inseridos. Fazia-se "necessário um sistema de comando constituído por poucas palavras e explicações, interrompendo o silêncio total por simples gestos, que rapidamente devem ser atendidos" (WANDERER, 2014, p. 126). Ou seja, nas aulas de matemática das escolas da imigração uma rede de forças foi estabelecida e atuava na subjetividade dos alunos disciplinando-os a fim de tornar as aulas um aparelho eficiente.

\section{CONSIDERAÇÕES FINAIS}

Como pode ser analisado nas narrativas dos participantes da pesquisa, no contexto do Rio Grande do Sul, havia uma tendência pela manutenção e preservação do Deutschtum vinculado a um sentimento de pertencimento étnico e cultural. No que se refere à forma de vida escolar, antes das medidas nacionalistas, os princípios norteadores do germanismo "eram transmitidos na escola, através 
do currículo, do conteúdo programático, dos livros didáticos, através da língua alemã e da ação dos professores" (FONSECA, 2007, p. 105).

Como discutido na seção de análise, os livros escolares eram uma ferramenta pedagógica utilizada nas escolas da imigração alemã. E, no caso específico dos livros de matemática, o seu uso foi considerado um ritual escolar marcado pelo disciplinamento. Além disso, nas narrativas apresentadas, os livros escolares utilizados antes da Campanha de Nacionalização eram considerados melhores do que aqueles que passaram a ser utilizados posteriormente a esse acontecimento. Isto porque os livros anteriores eram, em alguns casos, escritos em alemão, ou, mesmo que redigidos em português, traziam referências à cultura germânica, algo que era valorizado pelos alunos descendentes de alemães também nos livros escolares de matemática.

Além disso, da análise realizada pelas narrativas tomando como ferramenta as "grandes funções disciplinares" foucaultianas, foi argumentado que o uso do livro escolar nas aulas de matemática se constituía em um ritual nas escolas da imigração alemã, visto que o uso do livro escolar era instituído como uma prática recorrente, não era ditado apenas pelo professor, mas fazendo parte do que esperavam os alunos das aulas de matemática. Um ritual no qual mecanismos de poder atuavam sobre os alunos descendentes de imigrantes alemães com vistas a disciplinar seus corpos.

Diante de tais considerações, foi possível considerar que, no período da Campanha de Nacionalização, mesmo com as imposições e proibições do Estado que buscava uma unidade nacional, os princípios norteadores do Deutschtum foram, em alguns casos, preservados e, até mesmo, reforçados em forma de rituais escolares "adaptados" às condições impostas pelas medidas nacionalistas. Ou seja, o Deutschtum permaneceu operando como uma tecnologia na produção de uma subjetividade específica na forma de vida escolar dos imigrantes alemães e seus descendentes. Isto porque essa tecnologia estabelecia um conjunto de princípios e regras que atuava na relação do ser consigo e com os outros e constituía um modo de ser que possuía particularidades relacionadas aos valores, mitos e tradições de uma nacionalidade alemã. 
O uso de livros escolares de matemática nas escolas da imigração alemã durante a Campanha de Nacionalização

\section{REFERÊNCIAS}

BIEMBENGUT, Maria Salett; GAERTNER, Rosinéte. Livro didático de matemática de escola teuto-brasileira: considerações sobre a obra de Ferdinand Hackbart, Konrad Glau e Hermann Lange de 1906. Revista Brasileira de História da Matemática, v. 10, n. 20, p. 173-92, out./mar. 2011.

BRASIL. Decreto-lei n. 1545, de 25 de agosto de 1939. Dispõe sobre a adaptação ao meio nacional dos brasileiros descendentes de estrangeiros. Disponível em: <http://www2. camara.leg.br/legin/fed/declei/1930-1939/decreto-lei-1545-25-agosto-1939-411654publicacaooriginal-1-pe.html>.

. Decreto-lei n. 1006, de 30 de dezembro de 1938. Estabelece as condições de produção, importação e utilização do livro didático. Disponível em: <http://www2. camara.leg.br/legin/fed/declei/1930-1939/decreto-lei-1006-30-dezembro-1938-350741publicacaooriginal-1-pe.html>.

. Decreto-lei n. 868 de 18 de novembro de 1938. Cria, no Ministério da Educação e Saúde, a Comissão Nacional de Ensino Primário. Disponível em: <http://www2. camara.leg.br/legin/fed/declei/1930-1939/decreto-lei-868-18-novembro-1938-350829publicacaooriginal-1-pe.html>.

. Decreto-lei n. 406, de 4 de maio de 1938. Dispõe sobre a entrada de estrangeiros no território nacional. Disponível em: <http://legislacao.planalto.gov.br/legisla/legislacao. nsf/Viw_Identificacao/DEL\%20406-1938?OpenDocument>.

BREDEMEIER, Maria Luísa Lenhard. O português como segunda língua nas escolas da imigração alemã: um estudo do Jornal da Associação de Professores Teuto-Brasileiros Católicos do Rio Grande do Sul (1900-1939). 2010. Tese (Doutorado em Educação) Universidade do Vale do Rio dos Sinos, São Leopoldo, 2010.

DREHER, Martin. O Estado Novo e a Igreja Evangélica Luterana. In: MÜLLER, Telmo Lauro (Org). Nacionalização e imigração alemã. São Leopoldo: Ed. Unisinos, 1994. p. 27-66.

DUARTE, Cláudia Glavan. A "realidade" nas tramas discursivas da Educação Matemática Escolar. 2009. Tese (Doutorado em Educação) - Universidade do Vale do Rio dos Sinos, São Leopoldo, 2009.

FONSECA, Maria Angela Peter da. Estratégias para a preservação do germanismo (Deutschtum): gênese e trajetória de um collegio teutobrasileiro urbano em Pelotas (1898-1942). 2007. 158f. Dissertação (Mestrado em Educação) - Universidade Federal de Pelotas, Pelotas, 2007.

FOUCAULT, Michel. Do governo dos vivos: curso no Collège de France, 1979-1980 (excertos). São Paulo/Rio de Janeiro: Achiamé, 2010. 
. Vigiar e punir: o nascimento da prisão. 29. ed. Petrópolis: Editora Vozes, 2004. . Microfísica do poder. 17. ed. Rio de Janeiro: Graal, 2002.

. História da sexualidade 2: o uso dos prazeres. 8. ed. Rio de Janeiro: Edições Graal, 1998.

GERTZ, René. Ernaine. O perigo alemão. Porto Alegre: Editora da Universidade UFRGS, 1991.

$J \varnothing$ RGENSEN, Kenneth Mølbjerg; BOJE, David M. Resituating narrative and story in business ethics. Business Ethics: A European Review, v. 19, n. 3, p. 253-64, jul. 2010.

J RGGENSEN, Kenneth Mølbjerg; NUNEZ, Heilyn Camacho. Ethics and organizational learning in higher education. The International Conference on Higher Education proceeding, 2010.

KREUTZ, Lúcio. Escolas étnicas no Brasil e a formação do Estado Nacional: a nacionalização compulsória das escolas dos imigrantes (1937-1945). Poiésis, Unisul, Tubarão, v. 3, n. 5, p. 71-84, jan./jun. 2010.

KREUTZ, Lúcio. Livros escolares e imprensa educacional periódica dos imigrantes alemães no Rio Grande do Sul, Brasil, 1870-1939. Revista Educação em Questão, Natal, v. 31, n. 17, p. 24-52, jan./abr. 2008.

KREUTZ, Lúcio. A representação de identidade nacional em escolas da imigração alemã no Rio Grande do Sul. História da Educação (UFPel), Pelotas, v. 3, n. 5, p. 141-65, 1999.

. Material didático e currículo na escola teuto-brasileira do Rio Grande do Sul. 1. ed. São Leopoldo: UNISINOS, 1994.

LORENZ, Karl M.; VECHIA, Ariclé; FERREIRA, Antonio Gomes. A escola alemã versus as políticas educacionais nacionais na primeira metade do século XX: transformando imigrantes alemães em cidadãos brasileiros. Education Faculty Publications, v. 1, n. 1, p. 1-17, 2008.

MAURO, Suzeli. Uma história da matemática escolar desenvolvida por comunidades de origem alemã no Rio Grande do Sul no final do século XIX e início do século XX. 2005. 251f. Tese (Doutorado em Educação Matemática) - Universidade Estadual Paulista, São Paulo, 2005.

PAIVA, César. Escola de língua alemã no Rio Grande do Sul: o nazismo e a política de nacionalização. In.: FIORI, N. A. (Org.). Etnia e educação: a escola "alemã" do Brasil e estudos congêneres. Florianópolis: UFSC, 2003.

QUADROS, Claudemir de. Reforma, ciência e profissionalização da educação: o Centro de Pesquisas e Orientação Educacionais do Rio Grande do Sul. 2006. Tese (Doutorado em Educação)- Universidade Federal do Rio Grande do Sul, Porto Alegre, 2006. 
RAMBO, Arthur Blásio. A escola comunitária teuto-brasileira católica. 1. ed. São Leopoldo: UNISINOS, 1994.

SEYFERTH, Giralda. Nacionalismo e identidade étnica: ideologia germanista e o grupo étnico teuto-brasileiro numa comunidade do Vale do Itajaí. 1. ed. Florianópolis: FCC, 1982. WANDERER, Fernanda. Educação Matemática, jogos de linguagem e regulação. São Paulo: Editora Livraria da Física, 2014.

\section{Sobre a autora:}

Débora de Lima Velho Junges: Doutora e Mestre em Educação pela Universidade do Vale do Rio dos Sinos (Unisinos). Licenciada em Matemática pela mesma universidade. Técnica em Assuntos Educacionais no Instituto Federal Catarinense, campus Fraiburgo. E-mail: deborajunges@gmail.com

\section{Recebido em dezembro de 2017.} Aprovado em junho de 2018. 
